\title{
Delivering contraceptive vaginal rings: Review of postpartum and postnatal care programs in Nigeria
}

\author{
Godwin Unumeri \\ Population Council \\ Salisu Mohammed Ishaku \\ Population Council
}

Follow this and additional works at: https://knowledgecommons.popcouncil.org/departments_sbsr-rh

Part of the Demography, Population, and Ecology Commons, Family, Life Course, and Society Commons, International Public Health Commons, Maternal and Child Health Commons, and the Women's Health Commons How does access to this work benefit you? Let us know!

\section{Recommended Citation}

Unumeri, Godwin and Salisu Mohammed Ishaku. 2015. "Delivering contraceptive vaginal rings: Review of postpartum and postnatal care programs in Nigeria." Abuja: Population Council. 


\section{Review of Postpartum and
Postnatal Care
Programs in Nigeria Postpartum and
Postnatal Care
Programs in Nigeria Postpartum and
Postnatal Care
Programs in Nigeria}

Godwin Unumeri

Salisu Ishaku 


\section{Popuration \\ Ideas. Evidence. Impact.}

The Population Council confronts critical health and development issues-from stopping the spread of HIV to improving reproductive health and ensuring that young people lead full and productive lives. Through biomedical, social science, and public health research in 50 countries, we work with our partners to deliver solutions that lead to more effective policies, programs, and technologies that improve lives around the world. Established in 1952 and headquartered in New York, the Council is a nongovernmental, nonprofit organization governed by an international board of trustees.

Population Council

House 4, No. 16, Mafemi Crescent

Off Solomon Lar Way

Federal Capital Territory

Abuja

Nigeria

Tel: +234092914878

Fax: +234806778 7750

www.popcouncil.org

Suggested citation: Unumeri, G., S. Ishaku. 2015. “Delivering Contraceptive Vaginal Rings:

Review of Postpartum and Postnatal Care Programs in Nigeria." Abuja: Population Council.

(C) 2015 The Population Council, Inc. 


\section{Table of Contents}

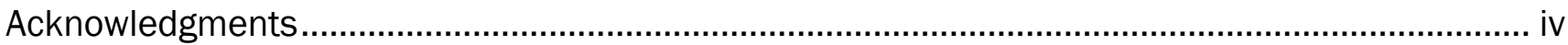

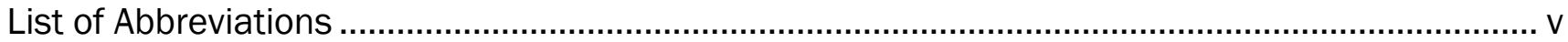

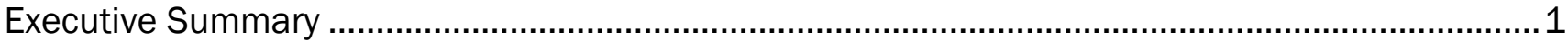

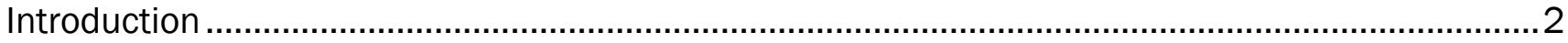

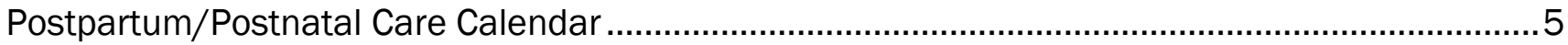

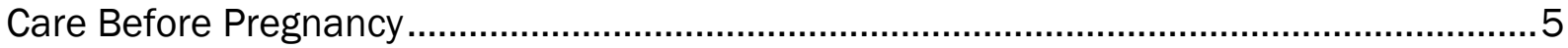

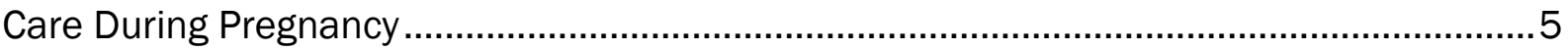

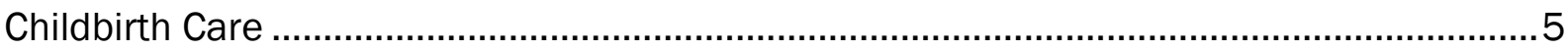

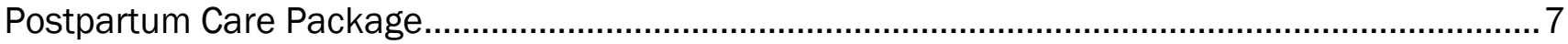

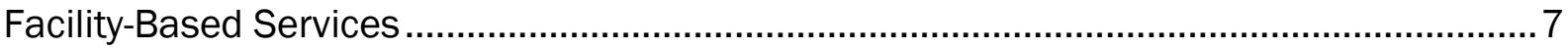

Community-Based Services........................................................................................ 7

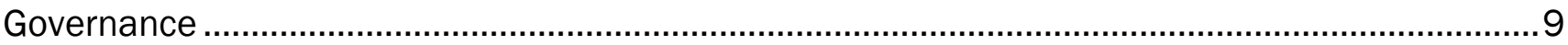

Elements of Health System Structure for Postpartum/Postnatal Care Strategies ...................... 11

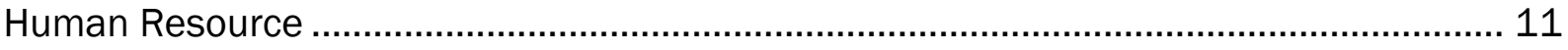

Financing and Resource Allocation Strategies ..................................................... 11

Availability and Use of Clinical- and Community-Level Guidelines ................................ 12

Life-saving commodities for PPC/PNC Nigeria ........................................................ 13

Integration of PPC/PNC Services into MCH/FP/Nutrition ...................................................... 10

Prospect for vaginal rings in the context of PPC/PNC programs in NIgeria...................... 14

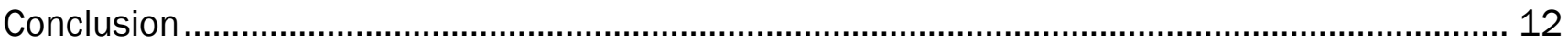

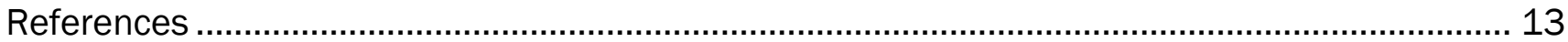




\section{Acknowledgments}

We acknowledge the contribution of the officials of the Federal Ministry of Health who availed themselves to us for consultations in the course of writing this document. We also acknowledge the support we received from staff members of various local and international non-for-profit organizations, too numerous to mention, for their time and effort in proving clarification on some important facts contained in this document. 


\section{List of Abbreviations}

$\begin{array}{ll}\text { ACCESS } & \text { Access to Clinical \& Community Maternal, Newborn and Women Health } \\ \text { ANC } & \text { Antenatal Care } \\ \text { BCG } & \text { Bacille Calmette-Guérin } \\ \text { CC } & \text { Continuum of Care } \\ \text { CPR } & \text { Contraceptive Prevalence Rate } \\ \text { EC } & \text { Emergency Contraceptive } \\ \text { EmOC } & \text { Emergency Obstetric Care } \\ \text { FGoN } & \text { Federal Government of Nigeria } \\ \text { FMoH } & \text { Federal Ministry of Health } \\ \text { FP } & \text { Family Planning } \\ \text { FP/MNCH-N } & \text { Family Planning/Maternal, Neonatal, Child Health and Nutrition } \\ \text { HIS } & \text { Health Information System } \\ \text { HIV } & \text { Human Immunodeficiency Virus } \\ \text { HMIS } & \text { Health Management Information System } \\ \text { HRH } & \text { Human Resource for Health } \\ \text { ICPD } & \text { International Conference on Population and Development } \\ \text { IMNCH } & \text { Integrated Maternal, Newborn and Child Health } \\ \text { IPT } & \text { Intermittent Preventive Therapy } \\ \text { KMC } & \text { Kangaroo Mother Care } \\ \text { LARC } & \text { Long-acting Reversible Contraceptives } \\ \text { LSCs } & \text { Life-Saving Commodities } \\ \text { MCH } & \text { Maternal and Child Health } \\ \text { MCHIP } & \text { Maternal and Child Health Integrated Project } \\ \text { MDG } & \text { Millennium Development Goals } \\ \text { MgSO4 } & \text { Magnesium Sulphate } \\ \text { NDHS } & \text { Nigeria Demographic and Health Survey } \\ \text { NES/EE } & \text { Nestorone/Ethinyl Estradiol } \\ \text { NICE } & \text { National Institute of Clinical Excellence } \\ \text { NHP } & \text { National Health Policy } \\ \text { NHSDP } & \text { National Health Strategic Development Plan } \\ \text { OPVO } & \text { Oral Polio Vaccine 0 } \\ \text { OPV1 } & \text { Oral Polio Vaccine 1 } \\ \text { PCVR } & \text { Progesterone Contraceptive Vaginal Ring } \\ \text { PMTCT } & \text { Prevention of Mother-to-Child Transmission } \\ \text { PMVs } & \text { Patent Medicine Vendors } \\ \text { PNC } & \text { Postnatal Care } \\ \text { PPC } & \text { Postpartum Care } \\ \text { PPFP } & \text { Postpartum Family Planning } \\ \text { SURE-P } & \text { Subsidy Re-investment and Empowerment Program } \\ \text { SURE-P } & \text { Subsidy Re-investment \& Empowerment Program-Maternal \& Child Health } \\ \text { MCH } & \\ & \end{array}$


TB

TFR

TSHIP

UNICEF

UNFPA

USAID

WHO
Tuberculosis

Total Fertility Rate

Targeted States High Impact Project

United Nations Children's Fund

United Nations Population Fund

United States Agency for International Development

World Health Organization 


\section{Executive Summary}

Postpartum and postnatal care programs are carefully selected maternal and child health interventions for maximizing the wellbeing of mothers and their babies. As the name implies, postpartum period technically refers to the period of time between the delivery of a baby and up to six weeks thereafter. This is a crucial period for the mother and the baby. While the mother is transitioning back to her pre-pregnancy state, the baby must adjust to the new 'hostile' extra-uterine environment. Although this is a routine physiological process, it may go awry with life-threatening consequences for the mother and her baby, hence the need for conscious efforts to support the pair. There is now a global standard of care outlining the minimum package for effective care. Accordingly, under the integrated maternal, neonatal and child health strategy, the Federal Ministry of Health stipulates a package of interventions for women and children which is available for childbirths that occur both in the health facilities and the communities. The government has invested heavily in this undertaking, and an increasing number of commitments are being made annually. Presently, Nigeria has developed a costed plan for scaling-up the recommendations of the United Nations Committee on Life-saving Commodities for Women and Children. Family planning commodities are now available free of charge at all public clinics and hospitals, and there is ambition of raising the contraceptive prevalence rate, including during postpartum period, from its current $10 \%$ to $36 \%$ by 2018 . For this to succeed, the range of contraceptive options for women after childbirth must be widened to cater for the needs of every woman. Population Council, with a grant from USAID, is working to introduce an additional method of contraception in Nigeria - the Progesterone contraceptive vaginal ring (PCVR). The PCVR is administered vaginally but acts systemically to inhibit ovulation, a major mechanism for its contraceptive effect. The PCVR contains natural progesterone and is meant for breastfeeding women to augment lactational amenorrhea. As postpartum family planning service is a major component of postpartum care services, the introduction of PCVR in Nigeria can potentially influence hugely on the success of this package of care by ensuring that women's options and access for contraceptives during breastfeeding period are expanded. This document reviews the prospect of integrating the PCVR into the existing postpartum program services for the betterment of women and their families in Nigeria. 


\section{Introduction}

Postpartum Care (PPC)/Postnatal Care (PNC) services are constellation of critical care bundles for women and their newborns during the period following childbirth. Essentially, the post-childbirth phase represents the time during which mothers are fully restored to their pre-pregnancy states, including involution of the uterus, acquire relevant information to nurture their newborns and gradually integrate their babies into the family, and a period of rapid adaptation for the newborns to the extra-uterine environment. This is fragile time period for both the mothers and the babies and requires meticulous monitoring. The World Health Organization (WHO) defines PPC as "care for the woman provided in the postpartum period," that is, "from complete delivery of the placenta to 42 days after delivery" (WHO, 2006).

The $\mathrm{MOH} /$ Nigeria developed 'the Integrated Maternal, Newborn and Child Health (IMNCH) strategy (2007) to improve maternal, neonatal and child health, including postpartum health. The PPC strategy includes a number of interventions for the mother and baby. Interventions aimed at the mother include educational and service-related efforts such as promotion of healthy habits, recognition of danger signs during pregnancy and following childbirth (vagina bleeding, fever, dizziness and blurring of vision, among others), promotion of exclusive breastfeeding, vitamin A supplementation, Prevention of Mother-to-Child Transmission of HIV and provision of family planning information, especially in postpartum period. Interventions aimed at babies include birth registration, helping babies to breathe, drying the newborn, sterile cord clamping and hygiene, routine immunization, eye care, skin-to skin contact between baby and mother and special care for children with low birth weight (FMoH, 2007).

To ensure effective service uptake, especially postpartum family planning, community-based education programs to create more demand for services are critical components of these efforts. For example, only $22 \%$ of rural women deliver at health facility under the care of skilled providers, and are potentially able to receive significant postpartum care (NDHS, 2013), although there is regional disparity as $15 \%$ and $78 \%$ facility deliveries occur in South East and North West respectively (NDHS, 2013). Nevertheless, the present commitments of the government of Nigeria to increase uptake of maternal health services through the Subsidy Re-investment and Empowerment Program (SURE-P) and related health projects are important major steps.

As the Population Council conducts a series of activities as prelude to eventual introduction of the Progesterone Contraceptive Vaginal Ring (PCVR) in sub-Saharan Africa, including Nigeria, the detailed evaluation of the postpartum program environment is very important. Understanding the prevailing postpartum and postnatal care landscapes will be crucial in determining how best this relatively new contraceptive innovation would be placed within the existing framework. This document reviews the status of various postpartum and postnatal programs in Nigeria, the feasibility of leveraging the ongoing policy and program opportunities to integrate the PCVR within the Nigeria's post-delivery care environment for the wellbeing of mothers and their infants. Likely challenges that may be encountered include ineffective linkages between the existing services and lack of quality data for monitoring and evaluation. 


\section{Postpartum/Postnatal Care Calendar}

As childbirth, within the context of standard care, can take place either in health facility or at home, two different scenarios are recommended - community and facility-based, although facility delivery is preferred (NICE, 2007). Evidence suggests that outcomes for the two settings are comparable (Leslie \& Romano, 2007), but when complications occur, births occurring in hospitals may have better outcomes (NICE, 2007). Consequently, the probability of births occurring both at the community and at health facility is factored into the decision-making process as to when postnatal care visits take place.

For births that occur in the community, it is highly recommended that the mothers and their babies visit health facility for postpartum/postnatal care within the first 24 hours (FMoH, 2011). This is also in line with the recommendation of the World Health Organization (WHO, 2006). And for the deliveries occurring at health facilities without complication, mothers and babies should continue to receive care at facility for at least 24 hours before discharge (WHO, 2013). Subsequently, the suggested care pathways for both the facility and community deliveries are similar. Both the FMoH (2011) and World Health Organization (2013) recommend further visits for the mothers and the babies - on day 3, between days $7-14$ and at 6 weeks postpartum. More frequent visits may be arranged, as deemed necessary, for sick, small and high-risks babies (FMoH, 2011). For the mothers, these visits and consultations provide opportunities to address pertinent concerns and for providers to establish the following; the presence of abnormal vaginal bleeding, lochia quality, perineal pain or swelling, problems with passing urine, fever, uterine involution, persistent or recent rise in blood pressure and opportunities to discuss contraception and nutrition issues. While discussion around contraception starts right in the pre-natal period, the sixth week postpartum visit provides a last opportunity for the woman to receive counseling on family planning and to make an informed decision. For breastfeeding women, progestogen hormonal contraceptives, including PCVR, are started at or after 6 weeks postpartum. This timeline is, therefore, very empowering for women who intend to start a contraceptive method in the immediate postpartum period.

For the babies, the visits provide the opportunities to assess whether lactation is initiated, established and exclusive, whether the babies are maintaining good general health, whether there is developing or unresolving jaundice, whether appropriate vaccines were given according to the national guideline (e.g. BCG, OPVO, and OPV1), whether vitamins A and K supplements were given, and for promotion of cord and skin care, and for vital registration. Since pediatricians pay particular attention to the issue of lactation when assessing the babies during this visit, this contact could serves as potentially linking opportunity to refer women for postpartum family planning, particularly the PCVR, whose efficacy is inseparably linked to breastfeeding episodes.

Postnatal visits to pediatrician are also other opportunities for women to be referred for vaccination of their babies and other related services, including family planning. The trend for babies who received full vaccination coverage has steadily increased in Nigeria, rising from 13\% in 2003 to 25\% in 2013 (NDHS, 2013). On the service integration framework, women who bring their children for vaccination services can be easily referred for information on postpartum family planning.

In Nigeria, services are provided on a 'continuum of care' framework, and postpartum health services starts from pre-conception through pregnancy, childbirth and in the postpartum period. 
These phases are briefly described below:

\section{CARE BEFORE PREGNANCY}

The rationale is that the nutrition, education and health status of women before pregnancy affect the outcome of their pregnancies. Optimizing women's baseline health and social condition before embarking on pregnancy significantly benefits the health of the mothers and their babies, not only during pregnancy, but after delivery and beyond. Consequently, the FMoH recognizes pre-conception care as a critical component of health care for women of reproductive age, with the main goal of providing health-promotion services, screening and interventions for women before pregnancy to reduce risk factors that might affect subsequent pregnancies (FMoH, 2010). This program has been recently introduced and hence its impact is not known as yet. What is presently known is that increasing numbers of women are recognizing and utilizing pre-conception care as a component of overall care for pregnant women. By and large, as this opportunity brings women in contact with facilities, it is expected to increase their health-seeking behaviors and utilization of health services including family planning.

\section{CARE DURING PREGNANCY}

Care for pregnant women is a crucial component of the service delivery package. As the Ministry of Health document on integrated maternal, neonatal child health states: "if a woman is unable to access adequate antenatal care (ANC), she cannot benefit from essential preventive care" (FMoH, 2007). Under the focused antenatal care framework, pregnant women are expected to make at least four antenatal visits to clinics to receive essential evidence-based services. In Nigeria, these interventions include identification and management of obstetric complications such as preeclampsia, administering essential vaccines such as tetanus toxoid, receive folic acid and iron supplementation tablets to prevent and or treat anemia in pregnancy, Intermittent Preventive Therapy (IPT) to prevent malaria in pregnancy and many other obstetrics interventions to prevent Mother-toChild Transmission of HIV (PMTCT). A recent development in the way ANC service is being delivered is the integration of tailored messages to improve uptake of postpartum family planning for birth spacing. This is important as one-third of married men and $40 \%$ of men want to wait at least two years before their next birth (NDHS, 2013). However, nearly one-third of all births occur less than two years after the last birth, indicating unmet need for spacing. These are potential users of postpartum contraceptives. The postpartum family planning message during the ANC and postpartum visits needs to be intensified and channeled appropriately. Fortunately, $67 \%$ of pregnant women receive some form of skilled ANC (NDHS, 2013), and may avail themselves of these messages.

\section{CHILDBIRTH CARE}

Childbirth and the period immediately after it are delicate in the continuum of care because this is when most maternal and neonatal deaths occur. The IMNCH strategy recognizes that risks associated with pregnancy and childbirth, such as fistula, are exacerbated by the lack of access to skilled delivery compounded by a 'culture of silence' during labor. The failure to take appropriate, timely action can lead to life-threatening consequences of obstructed labor and hemorrhage (FMoH, 2007). Therefore, the IMNCH strategy seeks to increase delivery at health facilities under the supervision of qualified health caregivers in order improve the outcomes for the mother and baby. Interventions at various levels starting from pregnancy support to intra-partum care build up into packages of care during postpartum period as a continuum. 


\section{Postpartum Care Package}

Since a high proportion of women deliver at home, the FMoH has designed two different service packages - one for home deliveries and the other for facility deliveries.

\section{FACILITY-BASED SERVICES}

Services provided on the platform of health facilities are carefully differentiated for newly delivered mothers and their newborn:

Facility-Based PPC Package for Mothers

At the hospital, mothers are provided with aspects of care that are both preventive and promotional to health. These include provision of FP information, education on danger signal recognition (bleeding, infections and developing or persistent hypertension), promotion of exclusive breastfeeding, Prevention of Mother-to-Child Transmission of HIV (PMTCT) and birth registration.

\section{Facility-Based PNC Package for Newborn Babies}

Care provided for newborns at the hospital in Nigeria cover childhood illnesses, including prevention of HIV infection, additional care for preterm babies, including Kangaroo Mother Care (KMC), emergency care for newborns and administration of BCG and OPVO vaccines before the child leaves hospital. The child is also scheduled to return at specific time to receive other vaccination.

\section{COMMUNITY-BASED SERVICES}

Health care services provided at the community level are also differentiated for mothers and newborns:

\section{Community-Based PPC Package for Mothers}

The content of this package includes promotion of healthy behaviors, early detection of danger signals and FP information and referral, prevention and or treatment of postpartum hemorrhage and referral.

\section{Community-Based PNC Package for Newborn Babies}

Community-based care for newborns focuses on hygiene especially around cord and skin care, warmth, exclusive breastfeeding together with appropriate complementary feeding when necessary, recognition of danger signals, prevention of dehydration with oral rehydration salt and case management for pneumonia, malaria, and neonatal sepsis where referral system is not available or feasible.

However, despite this seemingly organized pattern of care for mothers and their babies, some aspects of this care pathway are not always implemented or the intended benefits never reach the target population as conceptualized, irrespective of the birth setting in question. Most of these services are provided by secondary and primary health facilities which are under state and local government authorities. So, what services are available varies from state to state and from local one government council to another. But in general, urban facilities tend to have more complete and better-functioning systems than rural facilities. 


\section{Governance}

Health care provision is under the concurrent legislative list in the Constitution of the Federal Republic of Nigeria. As autonomous entities that manage their own resources, the three tiers of government (Federal, State and Local Government) formulate and implement policies, which often overlap, to regulate and provide health services within their respective jurisdictions. But for descriptive purposes, the Federal Government of Nigeria (FGN) provides the overall policy framework and set standards for quality assurance and training (FMoH, 2004). The FGN is also responsible for implementing national programs on immunization and funding of tertiary health facilities in Nigeria. On the other hand, the states and the Federal Capital Territory (FCT) administrations handle the policy-making process, personnel financing and provide current and capital investment for tertiary and secondary facilities within their jurisdiction. And lastly, the 774 Local Government Areas (LGAs) manage primary health care facilities at the lowest level of governance. Other stakeholders with significant impact on the health sector are private sector, non-for-profit organizations that operate at the three levels of care and the traditional sector that provides an estimated $80 \%$ of the health care in Nigeria (Larbi et al. 2004). This complex arrangement calls for close collaboration between the various tiers and functions within the health care sector. This coordination and close collaboration, however, are sometimes lacking, resulting in poor and disjointed health care delivery system. The World Health Organization (WHO, 2007) developed a health system performance enhancement framework to highlight key ingredients of an effective health system and enable member states to improve on health care governance as shown in the figure below:

Figure 1 : WHO Framework for Action

Health System Building Blocks

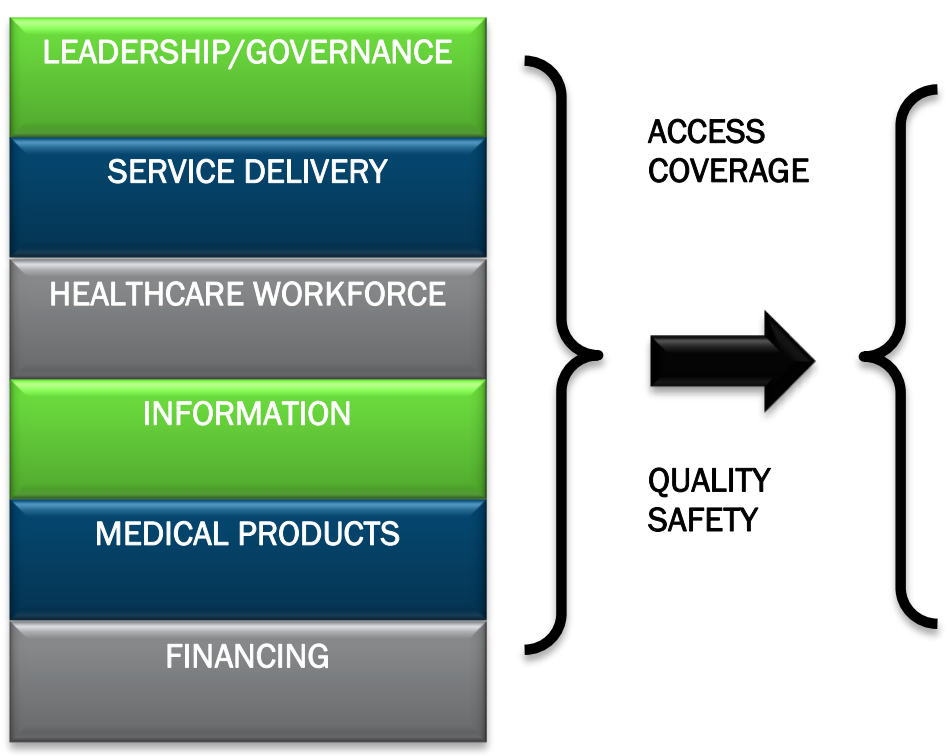

Overall Goals and Outcomes

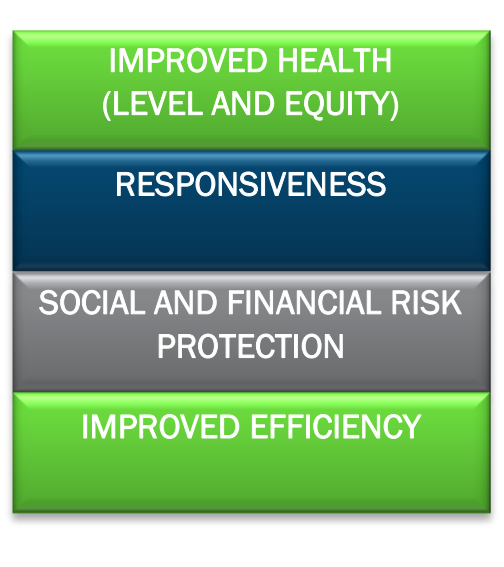

Adapted from WHO 2007 “Everybody business: strengthening health systems to improve health outcomes": WHO's framework for action. Document Production Services, Geneva, Switzerland. 
In Nigeria, the National Health Planning (NHP) is an integral component of the revised national health policy (2004). This policy provides a framework for assigning roles and responsibilities and defines the nature of coordination at various levels of health care management. It establishes priorities for the purpose of resource allocation. Accordingly, the Federal Government of Nigeria, through the $\mathrm{FMoH}$, is committed to increase spending and procurement for family planning commodities. To back this up, the ministry in partnership with Marie Stopes International has developed a service manual for nurses/midwives and CHEWs on long-acting family planning such as injectables, IUDs and implants. This would serve as a platform to aid the introduction of PCVR given that the government interest in this area is substantial. State governments, especially the northern states, are encouraged to create a budget line for family planning commodities with some promising results. For example, the states of Jigawa, Katsina, Kano and Kaduna have all budgeted for family planning commodities procurement in the current budget year.

\section{Elements of Health System Structure for Postpartum/Postnatal Care Strategies}

\section{HUMAN RESOURCES}

Nigeria's pool of Human Resources for Health $(\mathrm{HRH})$ compares only with those of Egypt and South Africa as the largest in Africa. In 2006, the FMoH data revealed that 39,210 and 124,629 registered doctors and nurses respectively practice in Nigeria, which gives a ratio of 30 doctors and 100 nurses per 100,000 people - the sub-Saharan Africa average was 15 doctors and 72 nurses per 100,000 people (WHO, 2006). Nevertheless, wide variation exists in workforce distribution, and so access to skilled health care providers varies among population groups in Nigeria. Typically, urban areas had more skilled health workers than rural areas. This is also reflected in poorer health indicators in the rural compared to urban areas. Factors such as attrition or relocation in search for better salaries and preference for an urban posting explain the existing distribution. The $\mathrm{FMoH}$ is embarking on reforms to improve the quality of and access to maternal and child health services in rural areas. This is through the adoption of task-shifting to allow a greater role for lower cadre providers in rural areas to provide essential services such as basic and comprehensive obstetric services and provision of Long-acting Reversible Contraceptives.

There is a special effort to raise the CPR in Nigeria to $36 \%$ by 2018 , and the role of community agents is seen as being a critical element. For example, the national policy now recognizes that $\mathrm{CHEWs}$ can provide injectables for rural women. There is also an ongoing pilot study in northern Nigeria to determine the feasibility of CHEWs to provide implants. The PCVR can easily fit into this framework when finally registered and introduced given the rising official interest in family planning, especially in the immediate postpartum period, and the community empowerment activities going on. The midwifery service scheme and the SURE-P for maternal and child health also stand out. They all seek to reach rural women and families with basic and essential obstetric care services. SURE-P also provides additional cash incentive based on conditionality (SURE-P MCH, 2012) for women who follow through their antenatal visits, delivery and postpartum care, including postpartum contraceptive. 
Lastly, the Patent Medicine Vendors (PMVs) are increasingly being involved in the provision of essential maternal health services, including provision of some family planning commodities. In Nigeria the PMVs are informal business owners licensed to sell patent or proprietary drugs. They are widely present in both rural and urban areas. Apart from providing barrier methods for contraception, Nigeria recognizes that they can re-issue contraceptive pills. Because of their ubiquitous distribution and close relationship with the environment they serve, they are likely to play an important role for distributing the PCVR when finally registered.

\section{FINANCING AND RESOURCE ALLOCATION STRATEGIES}

Just as the governing structure is based on the three-tier arrangement, the financing of health programs follows a similar pattern with federal, state and local governments funding health programs at their respective levels. This is complemented by funding from private sector, local and international non-governmental and faith-based organizations. But the total federal allocation to health as a percentage of the national budget has remained around 3.5\% since 2004. This has not been sufficient for effective running of the public sector that serves the majority of the population. As a result, up to $65 \%$ of health care costs come from people's out-of-pocket expenditure as of 2006 (WHO, 2006).

But the government's renewed commitment to contraception is a welcome development. For example, for the first time in the history of Nigeria, the FMoH created a budget line for family planning procurement amounting to about \$3 million per annum from 2012 to 2015. This was followed by a further pledge at the London Summit (2012) of $\$ 8.3$ million. Under its Subsidy Reinvestment and Empowerment Program (SURE-P), the Federal Government of Nigeria has earmarked a substantial amount of money for a maternal and child health project which aims to increase ANC attendance by $52 \%$, and skilled birth attendance and postpartum care services such as uptake of postpartum contraception by $63 \%$ each. Under this arrangement, a conditional cash transfer of $\$ 31.25$ would be made to mothers who meet certain preconditions, including at least 4 antenatal care visits and immediate postpartum care visits for the welfare of the mother and her baby, and receiving first immunization and child-spacing advice (SURE-P MCH, 2012). The above two commitments will significantly improve the quality of maternal and child health care in the country and pave the way for the uptake of life- saving strategies, especially those that target women in postpartum period.

\section{AVAILABILITY AND USE OF CLINICAL AND COMMUNITY-LEVEL GUIDELINES}

Insomuch as there are various levels of health care providers in Nigeria, there are accompanying guidelines for all of these cadres drawn to be specifically aligned with their respective needs and their job's complexities. Similarly, guidelines that solely address specific situations exist. Examples of clinical and community-level guidelines in Nigeria include:

- Antenatal Care Guideline

- Guidelines for the prevention and treatment of Postpartum Hemorrhage

- Family Planning National Training Manual for Physicians, \& Nurses/Midwives in the Private Sector

- Service manual on long-acting contraceptives for Nurse/Midwives and Community Health Extension Workers 
- National Family Planning/Reproductive Health Service Protocol, Revised Edition, 2009

- National Policy on HIV/AIDS (2009)

- National Tuberculosis and Leprosy Control Program Worker's Manual (2010)

- The National Guidelines for TB Infection Control (2008)

- National Guidelines for Setting-up Medical Laboratories in Nigeria (2012)

The availability of service-related guidelines, the evolving national task-shifting policy guideline and the service manual for long-acting methods that is being finalized would foster the evolution of society that is service-friendly for maternal and child health, but especially the future of family planning with emphasis on postpartum contraception.

\section{LIFE-SAVING COMMODITIES FOR PPC/PNC}

According to a report by the UN Commission on Life-Saving Commodities for Women and Children, the deaths of women and children could have been averted but inadequate supply of high-quality commodities, failure to regulate quality in-country, inadequate demand resulting from limited access and knowledge on proper use of health commodities, together with financial and health systems barriers, all continue to pose challenges (USAID, 2011). This clearly highlights the need to pay attention to Reproductive, Maternal, Newborn and Child Health issues along a continuum of Care (COC) - from pre-pregnancy to delivery, the immediate post-delivery period and childhood. In response to the UNCoLSC, Nigeria has come up with its strategy and roadmap for implementing its recommendations. Key among these commodities are magnesium sulphate (MgSo4), misoprostol, oxytocin, long-acting family planning commodities, chlorhexidine for cord care and zinc for management of diarrheal disease. This roadmap is already being implemented, and the inclusion of long-acting family planning can pave the way for the procurement of PCVR for distribution in the public sector when finally registered and introduced. 


\section{Integration of PPC/PNC Services into $\mathrm{MCH} / \mathrm{FP} /$ Nutrition}

Integration describes the "variety of managerial operational changes to health systems to bring together inputs, delivery, management, and organization of particular service functions to improve the service in relation to efficiency and quality, thereby maximizing use of resources and opportunities" (Briggs et al. 2006), In other words, integration is said to occur when an existing program or platform, say for example postpartum service, is leveraged to provide additional FP and immunization services. Both UNFPA and the Guttmacher Institute assert that integrating FP-MNCHNutrition services reduces the cost of service delivery by about $\$ 1.5$ billion compared to when $\mathrm{MNCH}-\mathrm{Nutrition}$ services are provided alone (Briggs et al. 2006).

An integration framework was piloted in Nigeria under the auspices of USAID-funded "Access to Clinical and Community Maternal, Neonatal and Women's Health Services/Maternal and Child Health Integrated Program (ACCESS/MCHIP) in northern Nigeria. This program demonstrated that it was possible within a relatively short period to increase utilization of health services; for example there was tripling of utilization of ANC, skilled birth delivery services and postpartum visits (Blumhagen et al. 2009). Taking a cue from this and similar integration programs, the FMoH of Nigeria developed a package of intervention services coined 'the National Integrated Maternal Newborn and Child Health Strategy' in order to ensure that health services reach women and children across a continuum-of-care framework. Any woman who delivers in health facilities will be linked-up to receive care at appropriate times such as child vaccination, postpartum contraception, and advice on maternal and infant nutrition. And women who deliver at home are encouraged to report to the nearest facility to be integrated into this network of health care delivery services.

\section{PROSPECT FOR VAGINAL RINGS IN THE CONTEXT OF PPC/PNC PROGRAMS IN NIGERIA}

Contraceptive Vaginal Rings (CVRs) are a new drug delivery system developed to provide contraceptives via the vaginal route. The PCVR contains natural progesterone and was developed purposely for breastfeeding women to augment lactational amenorrhea. The ring is inserted vaginally by the woman herself and can remain in place releasing active hormones for 3 months, and a breastfeeding woman can use up to 4 rings in the first year postpartum. Because of their simplicity of use (woman-initiated), they are suitable for environments without high-skilled family planning providers. These rings, therefore, have great potential within Nigeria's current PPC/PNC policies of deploying high-impact maternal and child health services for families in hard-to-reach areas. The ring can be easily integrated into the midwifery service scheme program and the subsidy re-investment and empowerment program for maternal and child health; all aim to increase access to quality maternal health services, including postpartum services and contraception.

Currently, the national CPR for modern methods is only $10 \%$. The government of Nigeria is committed to raising the CPR to $36 \%$ by 2018 . Since postpartum contraceptive use is also very low (13\%), increasing postpartum contraceptive use is paramount to the realization of this goal. The PCVR could play a major role in this respect, and preliminary results from an ongoing acceptability study show that PCVR is the preferred method of choice for first-time users of family planning and also among young clients. The growing unmet need for child-spacing and limiting implies that more contraceptive options are required for use by postpartum women both during breastfeeding period 
and thereafter, making the PCVR as a welcome innovation. Although majority of women want to space their birth for at least 24 months, up to one-third of women deliver at less than 24 months from the birth of their last child, indicating that more postpartum FP methods are required.

The current task-shifting policies is born out of the need to allow lower cadres health providers to provide essential commodities for the optimal implementation of the country's PPC/PNC policies, of which postpartum contraception is an integral component. The simple nature of these rings and their lower reliance on complex health system infrastructure mean that they can easily be deployed in the current policy efforts. In an environment plagued by shortage of health care institutions and qualified health care professionals, the PCVR could be conveniently distributed through available public and private health institutions, and could be dispensed over the counter by the PMVs in urban and rural areas.

Public sector users often express concern about the costs of contraceptive commodities. Presently, the national government has directed that contraceptive commodities obtained from the public sector should be free, and this policy augurs well for ring users in the public system. The commitment by the federal government to provide $\$ 3$ million annually for contraceptive procurement and the further $\$ 8.3$ million pledged at the London Summit for the same purpose demonstrate the country's interest in family planning, especially for public sector consumers. What is required for the government to procure any commodity is its inclusion in the essential medicine list. This can happen rapidly with PCVR as soon as it is pre-qualified by World Health Organization, and given the FMoH's interest in the new delivery system.

As maternal care is now being offered as a continuum starting from pre-conception care through postpartum period, transition from one stage to another is becoming increasingly easier. Accordingly, the ring can be introduced along this continuum with relevant information provided to women early in the pre-natal period. If a woman elects to use a ring during lactation, the PCVR will be available to her, and for women who choose to continue on the ring beyond breastfeeding period, the NES/EE is a suitable option. 


\section{Conclusion}

The combined commitments from the government of Nigeria and the international donor agencies such as USAID and UNFPA are putting the country on course to realizing its objectives of saving 1 million more lives and increasing its CPR to $36 \%$ by 2018 . A notable aspect of this commitment is the adoption and gradual implementation of the Integrated Maternal and Child Health Strategy at various levels of government. Fundamental to this strategy is the strengthening of postpartum aspect of the continuum, an area previously ignored. Since one of the key elements to this is the provision of contraception in postpartum period and beyond, the PCVR has a great role to play. This will be aided by the rapidly growing interest of the government in maternal health, the evolving taskshifting atmosphere in the country and the increasing willingness of federal government to increase spending on contraceptive commodities, procurement, and logistics. Other vaginal contraceptives, such as the NES/EE, can be introduced based on the success of the PCVR.

In summary, the existence of the following platforms augur well for the introduction of the PCVR in Nigeria: the availability of service delivery guideline in the community, the large unmet need for birth spacing, the ambitious attempt by the FMoH to increase the CPR by 26 percentage points in 5 years, the rising trends for women receiving full vaccination for their babies, the evolving continuum of care framework and the ubiquitous distribution of PMVs and CHEWs who could potentially provide the PCVR in both rural and urban settings. However, challenges such as the non-uniform implementation of the IMNCH strategy across states and local government councils and lack of quality data for monitoring and evaluation would have to be overcome. 


\section{References}

1. WHO (2006), Pregnancy, Childbirth, Postpartum and Newborn Care: A guide for essential practice, WHO, Geneva.

2. United Nations Population Funds (2007). Improving Maternal, Newborn and Child Health in Nigeria. Retrieved 29 August, 2014 from http://www.nigeria.unfpa.org/pdf/imnchfyer.pdf

3. Federal Ministry of Health (2007), Integrated Maternal, Newborn and Child Health Strategy (IMNCH).

4. Leslie MS, Romano A (2007). Birth can safely take place at Homes and in Birthing Centers. Journal of Perinatal Education, 16(1-Supplement), 81S-88S, doi: 10.1624/105812407X173236

5. National Institute of Clinical Excellence (2007). Intrapartum Care: Care of Healthy Women and their Babies during Childbirth. NICE Clinical Guideline 55.

6. Federal Ministry of Health (2010). National Guidelines for Prevention of Mother- to- Child Transmission of HIV. Fourth Edition; ISBN 978 - 166 - 412 - 6

7. Federal Ministry of Health of Nigeria (2004).

8. Larbi et al. (2004).

9. World Health Organization (2007). Everybody's Business: Strengthening Health System to Improve Health Outcome - WHO'S Framework for Action. Geneva:

10. Federal Ministry of Health (2010). National Strategic Health Development Plan; 2010-2015

11. WHO Statistical Information System

12.Subsidy Re-investment and Empowerment Program for Maternal and Child Health (2012). Project Implementation unit, the National Primary Health Care Development Agency. Mubi close, Area 11, Garki, Abuja, FCT.

13. Briggs CJ, Garner P. Strategies for integrating primary health services in middle and lowincome countries at the point of delivery. Cochrane Database of Systematic Reviews 2006, Issue 2. Art. No.: CD003318

14. Blumhagen D. Carol B. Muyiwa O. Olubumi O. Jack R. (2009). USAID/Nigeria Maternal, Child and Reproductive Health Program: Mid-term Evaluation. Global Health Technical Assistant Project

15. United State Agency for International Development (2011), FP-MNCH-Nutrition Integration Technical Consultation Conference Report. Retrieved August 17, 2014 from http://www.esdproj.org/site/DocServer/FP-MNCH Nutrition_Integration_Conference_Report_7.12.11_.pdf?docID=4161; Accessed 06-05-2014 



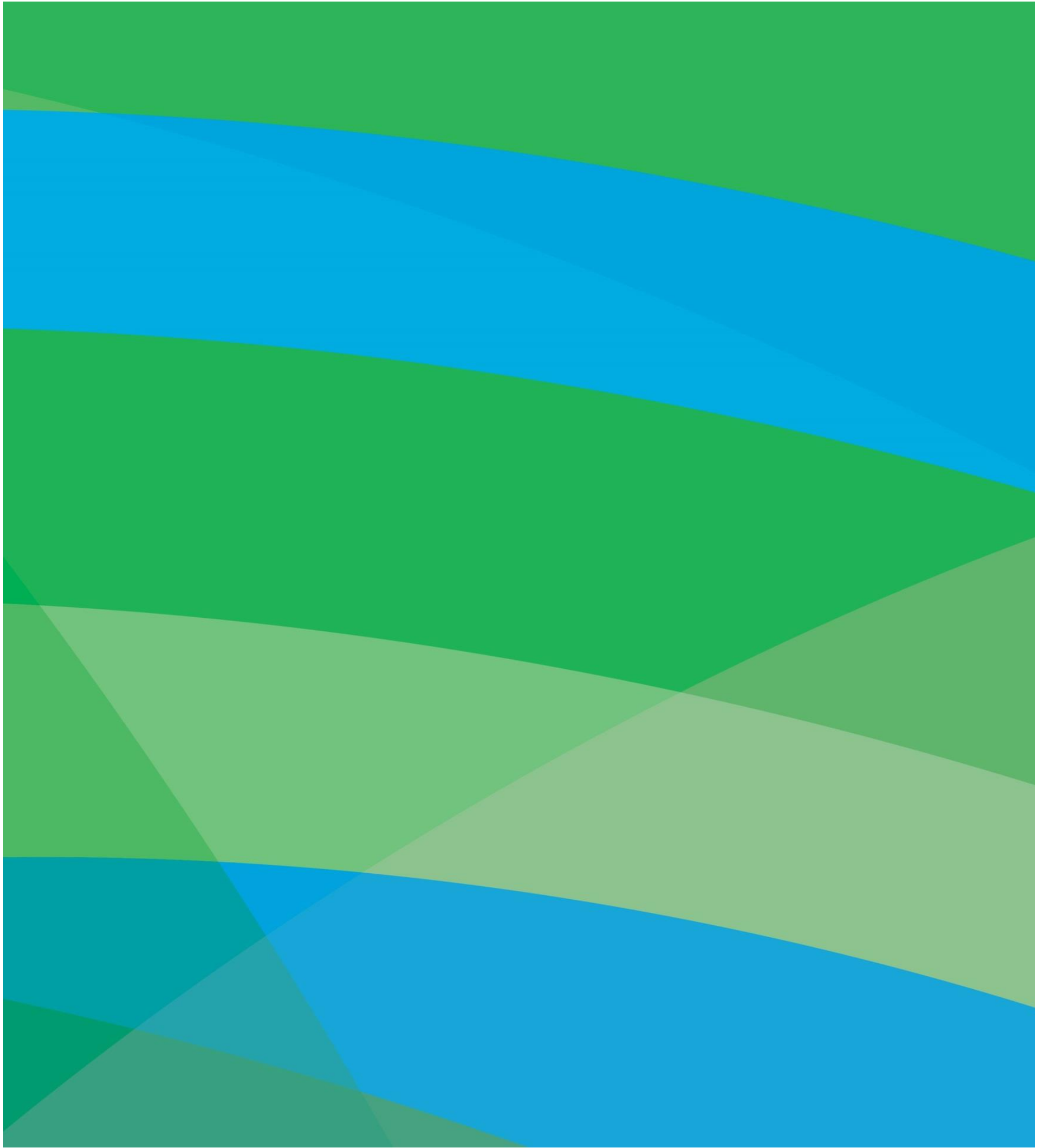

